\title{
Plant Extracts Inhibiting Biofilm Formation by Streptococcus mutans without Antibiotic Activity ${ }^{1}$
}

\author{
Youngseok $\mathrm{Ham}^{2}$ • Tae-Jong Kim $\mathbb{D}^{2, \dagger}$
}

\begin{abstract}
Streptococcus mutans causes oral diseases, including tooth decay, by producing a biofilm called plaque. Therefore, inhibition of biofilm formation is essential for maintaining oral health. Plants produce a variety of secondary metabolites, which act as starting sources for the discovery of new bioactive chemicals that inhibit biofilm formation of $S$. mutans. Previous studies have reported on chemicals with antibiotic activity for the inhibition of biofilm formation by $S$. mutans. In this study, nine plant extracts from Melonis Pedicellus, Agastachis Herba, Mori Cortex Radicis, Diospyros kaki leaves, Agrimoniae Herba, Polygoni Multiflori Radix, Lycopi Herba, Elsholtziae Herba, and Schizonepetae Spica were screened for the inhibition of biofilm formation from a plant extract library. The water-soluble compounds of the extracts did not affect cell growth but selectively inhibited biofilm formation. These results suggest that the selected plant extracts constitute novel biofilm formation inhibitors, with a novel biological mechanism, for improving oral hygiene.
\end{abstract}

Keywords: biofilm, plaque, Streptococcus mutans, plant extract, Mori Cortex Radicis

\section{INTRODUCTION}

Streptococcus mutans causes dental caries by attaching to gum and teeth surfaces and producing biofilm (plaque) and acid (Loesche, 1986; Ahn et al., 2008). The biofilm produced by $S$. mutans helps the bacterium and other microbes to attach oral surfaces, leading to diseases such as gingivitis and periodontitis. Therefore, $S$. mutans flourishing in the oral cavity may result in complications from additional infectious microorganisms (Ahn et al., 2008); these include endocarditis (Berbari et al., 1997), pneumonia (Scannapieco, 1999), systemic diseases such as cardiovascular disease (Beck et al., 1996; Li et al., 2000), and low birth weight and preterm birth rate (Buduneli et al., 2005). The microorganisms attached to biofilms are more resistant to physical, chemical, and biological treatments than the planktonic cells (Welin-Neilands and Svensater, 2007; Bowen and Koo, 2011). Therefore, it is important to inhibit biofilm formation to prevent various diseases in which $S$. mutans cannot be eliminated.

For removing biofilm in the oral cavity, physical methods (Loe, 2000), such as tooth brushing and flossing, and chemical methods (Wolff, 1985; Glassman et al., 2003; Paula et al., 2010), such as chlorhexidinebased oral cleansers, are used. Because physical methods often leave residual microorganisms, it is desirable to use chemical methods additionally to

\footnotetext{
${ }^{1}$ Date Received July 10, 2018, Date Accepted October 24, 2018

2 Department of Forest Products and Biotechnology, Kookmin University, Seoul 02707, Republic of Korea

† Corresponding author: Tae-Jong Kim (e-mail: bigbell@kookmin.ac.kr, ORCID: 0000-0002-7483-0432)
} 
efficiently eliminate biofilms. Most chemicals used in chemical hygiene modalities have high antimicrobial activity and sometimes exhibit side effects such as tooth coloring, tartar formation, and oral mucosal dissolution (Wolff, 1985; Eley, 1999). Continuous usage of chemical agents with bactericidal properties also alters the microbial flora in the oral cavity (Walker, 1996; Goncalves et al., 2007).

Recently, there has been growing interest in natural compounds that can inhibit bacterial growth or biofilm formation without such side effects (Dixon, 2001; Simoes et al., 2009; Saleem et al., 2010). Plants produce diverse secondary metabolites that protect them from herbivores, insects, microbes, and other plants (Harborne, 1990; Dixon, 2001) and possess additional biofunctions (Jeon et al., 2011; Palombo, 2011; Jeong et al., 2017; Jung et al., 2017; Nam et al., 2018). However, the extracted secondary metabolites depend on various extraction factors, such as time, temperature, and solvent, which eventually affect the efficacy of the resultant extracts (Liyana-Pathirana and Shahidi, 2005; Kim et al., 2017; Kim et al., 2018).

In this study, we screened plant extracts that specifically inhibited the biofilm formation of $S$. mutans without antibiotic effects.

\section{MATERIALS and METHODS}

\subsection{Plant extract library}

Dried selected plants were purchased from an herbal medicine shop (Jiundang, Seoul, Korea). These were ground to a size of $\leq 1 \mathrm{~mm}$ for extraction. The resultant plants powders (30 g) were mixed with methanol (300 $\mathrm{ml}$ ) and incubated at $50^{\circ} \mathrm{C}$ for $3 \mathrm{~h}$. After incubation, the residual plant powders were removed via filtration using Whatman ${ }^{\circledR}$ qualitative filter papers (Grade 1, GE Healthcare Life Science, Seoul, Korea). Filtered extracts were concentrated using a rotary evaporator (RV10,
IKA $^{\circledR}$ Korea, Ltd., Seoul, Korea). The semi-solid extracts were then dried for at $60^{\circ} \mathrm{C}$ for 1 week. Subsequently, the dried extracts were stored in a freezer at $-80^{\circ} \mathrm{C}$.

\subsection{Culture conditions for $S$. mutans}

S. mutans was generously provided by LG Household \& Health Care Ltd. (Daejeon, Korea) and was stored at $-80^{\circ} \mathrm{C}$ in $25 \%$ glycerol. Bacto ${ }^{\mathrm{TM}}$ brain heart infusion (BHI) broth was purchased from BD Biosciences Korea Ltd. (Seoul, Korea). BHI agar medium was prepared by adding $15 \mathrm{~g} / \mathrm{l}$ agar to BHI broth. BHI-S medium was prepared by supplementing BHI broth with $1 \%$ sucrose (Song et al., 2007). S. mutans was streaked onto BHI agar plate and cultured at $37^{\circ} \mathrm{C}$ for 2 days. A single colony was inoculated in $5 \mathrm{ml}$ BHI broth and incubated at $37^{\circ} \mathrm{C}$ for 1 day. The cell density was measured using Optizen 2120 UV plus spectrophotometer (Mecasys Co., Ltd., Daejeon, Korea) as the absorbance at $600 \mathrm{~nm}$.

\subsection{Preparation of plant extracts for screening of inhibitory effects}

Dried extracts were dissolved in methanol in a concentration of $50 \mathrm{~g} / \mathrm{l}$, followed by centrifugation at 13,000 rpm for $20 \mathrm{~min}$. The resultant supernatants were filtered using a syringe filter (cellulose acetate; $25 \mathrm{~mm}$ diameter, $0.2 \mu \mathrm{m}$ pore size; GVS Korea Ltd., Namyangju, Korea). The resultant extract library was stored at $-80^{\circ} \mathrm{C}$ until use.

\subsection{Plant extraction using various solvents}

The selected plants from the first screening were ground to a size of $\leq 1 \mathrm{~mm}$. The powders of nine selected plants (10 g each) were mixed with $100 \mathrm{ml}$ of water, $50 \%$ ethanol, or $95 \%$ ethanol and incubated at $50^{\circ} \mathrm{C}$ 
for $3 \mathrm{~h}$. The residual powders after incubation were removed via filtration using Whatman ${ }^{\circledR}$ qualitative filter papers. Each water extract was directly used for activity evaluation after filtration using a syringe filter (GVS Korea Ltd.) Additionally, 50\% and 95\% ethanol extracts were concentrated using RV10 rotary evaporator, following which water was added to the original volume. After centrifugation at 13,000 rpm for $20 \mathrm{~min}$, the water-soluble component of each extract was finally separated by filtration using a syringe filter (GVS Korea Ltd.). All prepared extracts were stored at $-80^{\circ} \mathrm{C}$.

\subsection{Quantitative analysis of biofilm}

The biofilm amount was quantitatively measured as previously described (Ham and Kim, 2016). The extracts ( $0.5 \mathrm{~g} / \mathrm{l})$ were added to the wells of a 96-well polyvinyl chloride microplate containing $100 \mu \mathrm{l}$ of BHI-S medium per well. S. mutans was inoculated in the wells at a cell density of 0.05 , as measured at an absorbance at $600 \mathrm{~nm}$. The microplates were incubated at $37^{\circ} \mathrm{C}$ for $24 \mathrm{~h}$ to permit biofilm formation. Cell density after $24 \mathrm{~h}$ was measured at $595 \mathrm{~nm}$ using Opsys $\mathrm{MR}^{\mathrm{TM}}$ microplate reader (Dynex Technologies Inc., Chantilly, VA, USA). Planktonic cells were rinsed with water, and $100 \mu \mathrm{l}$ of $1 \%$ crystal violet was added to each well and incubated at room temperature for $15 \mathrm{~min}$. The wells were then rinsed thrice with water, and 100 $\mu \mathrm{l}$ of $95 \%$ ethanol was added to each well. After allowing crystal violet to dissolve in the biofilm for $15 \mathrm{~min}$, the absorbance was measured at $595 \mathrm{~nm}$ using Opsys $\mathrm{MR}^{\mathrm{TM}}$ microplate reader.

\section{RESULTS and DISCUSSION}

\subsection{Inhibitory effects of methanol extracts on biofilm formation}

Various solvents, such as methanol, ethanol, acetone, and water, can be used to extract bioactive compounds
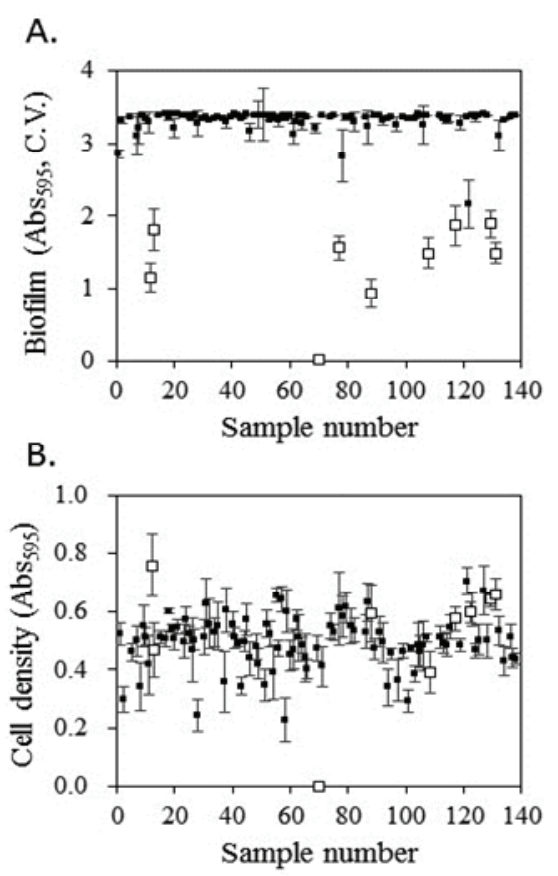

Fig. 1. Effects of all tested plant extracts on biofilm formation (A) and cell growth (B) of S. mutans were measured. Nine extracts that inhibited biofilm formation were selected, which are represented by open squares in both (A) and (B). Standard deviation was calculated from eight independent experiments. C.V. represents treatment with $1 \%$ crystal violet.

from plants. Among these, methanol is used to extract a wide variety of compounds (Dai and Mumper, 2010). The inhibitory activity of methanol extracts on biofilm formation by S. mutans was evaluated (Fig. 1). Among the 140 extracts that were tested, extracts from nine plants, Melonis Pedicellus (sample number: 12 in Fig. 1), Agastachis Herba (sample number: 13 in Fig. 1), Mori Cortex Radicis (sample number: 70 in Fig. 1), Diospyros kaki leaves (sample number: 77 in Fig. 1), Agrimoniae Herba (sample number: 88 in Fig. 1), Polygoni Multiflori Radix (sample number: 108 in Fig. 1), Lycopi Herba (sample number: 117 in Fig. 1), Elsholtziae Herba (sample number: 129 in Fig. 1), and Schizonepetae Spica (sample number: 131 in Fig. 1), 
inhibited biofilm formation by S. mutans.

The selected extracts, excluding Mori Cortex Radicis extract, did not significantly affect the growth of $S$. mutans. Mori Cortex Radicis extract exhibited strong antibacterial activity; therefore, this extract appeared to reduce biofilm formation by significantly reducing the number of bacterial cells. None of the other extracts exhibited growth-inhibitory activity; however, biofilm formation was selectively inhibited despite sufficient bacterial growth. Among the extracts excluding Mori Cortex Radicis extract, the strongest inhibition of biofilm formation were exhibited by Agrimoniae Herba (72\% inhibition) extract; the inhibitory activities of the remaining extracts on biofilm formation increased in the following order: Melonis Pedicellus, Polygoni Multiflori Radix, Schizonepetae Spica, Diospyros kaki leaves, Agastachis Herba, Lycopi Herba, and Elsholtziae Herba.

\subsection{Concentration-dependent inhibitory effects of methanol extracts on biofilm formation}

Inhibitory effects of nine selected methanol extracts on biofilm formation by $S$. mutans were measured via serial dilution (Fig. 2). The methanol extract of Mori Cortex Radicis, which exhibited both antimicrobial and biofilm formation inhibitory activities, displayed strong inhibitory activity at a low concentration of $0.0625 \mathrm{~g} / \mathrm{l}$. At a concentration of $0.03 \mathrm{~g} / \mathrm{l}$, the biofilm formation inhibitory activity was approximately $90 \%$ compared with approximately $24 \%$ at a concentration of 0.015 g/l. No inhibitory activity was observed at concentrations less than $0.0078 \mathrm{~g} / \mathrm{l}$.

Methanol extracts of Agastachis Herba, Lycopi Herba, Elsholtziae Herba, and Schizonepetae Spica did not exhibit significant inhibitory activity against biofilm formation at $0.25 \mathrm{~g} / \mathrm{l}$, reducing biofilm formation by $56 \%, 40 \%, 26 \%$, and $16 \%$, respectively. At a concentration of $0.13 \mathrm{~g} / \mathrm{l}$, the extracts of Mori
A.

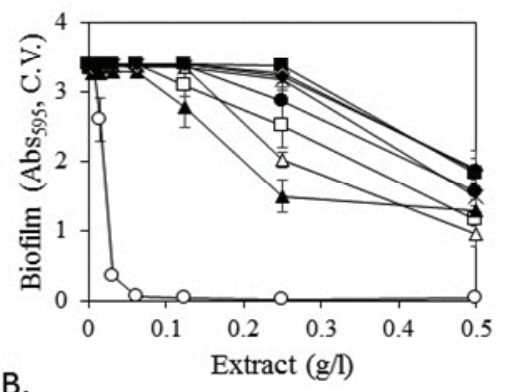

B.

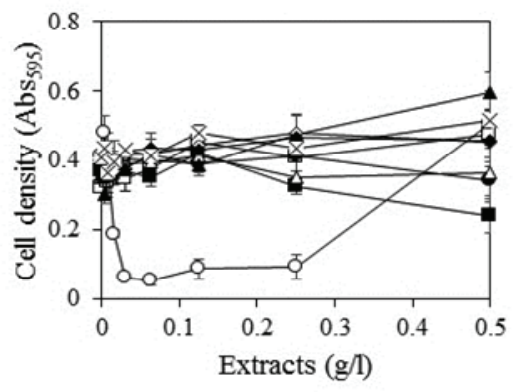

Fig. 2. Concentration-dependent effects of plant extracts on biofilm formation (A) and cell growth (B) by Streptococcus mutans were measured. Nine selected inhibitory extracts were Melonis Pedicellus $(\square)$, Agastachis Herba ( $\bullet$ ), Mori Cortex Radicis ( $O$ ), Diospyros kaki leaves $(\bullet)$, Agrimoniae Herba $(\triangle)$, Polygoni Multiflori Radix (A), Lycopi Herba $(\diamond)$, Elsholtziae Herba $(\diamond)$, and Schizonepetae Spica $(\times)$. Standard deviation was calculated from eight independent experiments. C.V. represents treatment with $1 \%$ crystal violet.

Cortex Radicis, Polygoni Multiflori Radix, and Melonis Pedicellus reduced biofilm formation by $99 \%, 13 \%$, and $9 \%$, respectively, whereas the remaining extracts displayed no inhibitory activity. At concentrations of less than $0.06 \mathrm{~g} / \mathrm{l}$, only Mori Cortex Radicis inhibited biofilm formation.

\subsection{Inhibitory effects of water and ethanol extracts on biofilm formation}

The nine selected plants were extracted with water 
Table 1. Biofilm formation by Streptococcus mutans in the presence of nine plant extracts

\begin{tabular}{ccccc}
\hline Solvent for extraction & Methanol & Water & $50 \%$ ethanol & $95 \%$ ethanol \\
\hline Control (without an extract) & $3.39 \pm 0.01$ & $3.37 \pm 0.05$ & $3.33 \pm 0.04$ & $3.38 \pm 0.03$ \\
Melonis Pedicellus & $1.15 \pm 0.20$ & $3.26 \pm 0.03$ & $3.41 \pm 0.01$ & $3.39 \pm 0.01$ \\
Agastachis Herba & $1.81 \pm 0.28$ & $3.34 \pm 0.01$ & $3.40 \pm 0.02$ & $3.41 \pm 0.01$ \\
Mori Cortex Radicis & $0.03 \pm 0.01$ & $3.33 \pm 0.01$ & $3.37 \pm 0.01$ & $3.37 \pm 0.01$ \\
Diospyros kaki leaves & $1.56 \pm 0.17$ & $3.33 \pm 0.01$ & $1.83 \pm 0.34$ & $3.38 \pm 0.01$ \\
Agrimoniae Herba & $0.94 \pm 0.20$ & $1.62 \pm 0.22$ & $1.08 \pm 0.08$ & $3.40 \pm 0.01$ \\
Polygoni Multiflori Radix & $1.29 \pm 0.21$ & $2.39 \pm 0.21$ & $1.45 \pm 0.18$ & $3.40 \pm 0.01$ \\
Lycopi Herba & $1.87 \pm 0.27$ & $3.40 \pm 0.01$ & $3.42 \pm 0.01$ & $3.40 \pm 0.01$ \\
Elsholtziae Herba & $1.89 \pm 0.18$ & $3.40 \pm 0.01$ & $3.41 \pm 0.01$ & $3.39 \pm 0.01$ \\
Schizonepetae Spica & $1.49 \pm 0.14$ & $3.40 \pm 0.01$ & $3.42 \pm 0.01$ & $3.41 \pm 0.01$
\end{tabular}

Data are presented as the absorbance at $595 \mathrm{~nm}$ following crystal violet staining. The mean and standard deviation were calculated from eight independent experiments.

and $50 \%$ and $95 \%$ ethanol. The inhibitory activity of water-soluble components isolated from the extracts was observed by redissolving these extracts in water (Table 1). Inhibitory effects on biofilm formation were observed for $50 \%$ ethanol extract of Diospyros kaki leaves (45\%), water extract of Agrimoniae Herba (52\%), $50 \%$ ethanol extract of Agrimoniae Herba (68\%), water extract of Polygoni Multiflori Radix (29\%), and 50\% ethanol extract of Polygoni Multiflori Radix (56\%). No inhibitory activity was observed for any of the $95 \%$ ethanol extracts.

The inhibitory activity of some extracts was further examined based on the concentration (Fig. 3). Regarding Mori Cortex Radicis, for which the methanol extract exhibited strong antibacterial activity and inhibitory activity against biofilm formation, water and 50\% ethanol extracts displayed neither of the two activities (Fig. 3A). In addition to the methanol extract, the 50\% ethanol extract of Diospyros kaki leaves inhibited biofilm formation (open circle in Fig. 3B). Specifically, at $0.425 \mathrm{~g} / \mathrm{l}$, the methanol extract of Diospyros kaki leaves inhibited biofilm formation by approximately $54 \%$, whereas the $50 \%$ ethanol extract displayed no inhibitory activity. Methanol, water, and 50\% ethanol
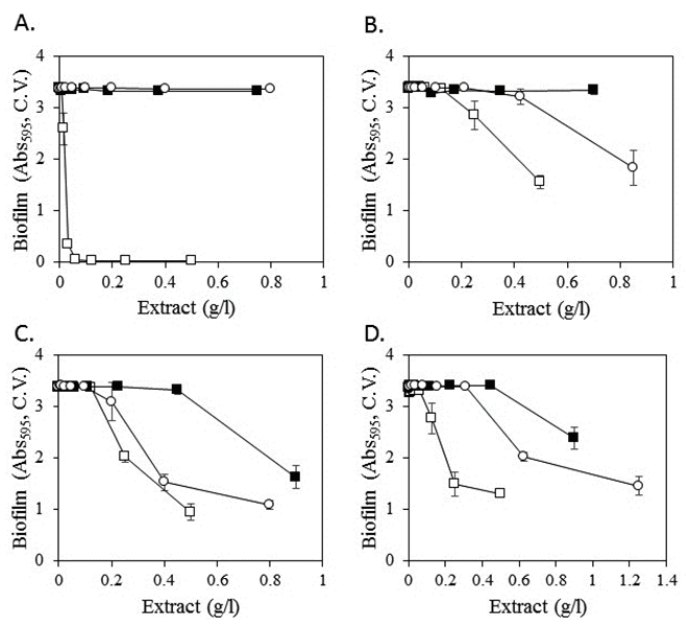

Fig. 3. Four plants, namely Mori Cortex Radicis (A), Diospyros kaki leaves (B), Agrimoniae Herba (C), and Polygoni Multiflori Radix (D), were extracted with methanol $(\square)$, water $(\square)$, or $50 \%$ ethanol $(\bigcirc)$. Standard deviation was calculated from eight independent experiments. C.V. represents treatment with $1 \%$ crystal violet.

extracts of Agrimoniae Herba and Polygoni Multiflori Radix inhibited biofilm formation (Fig. 3C and 3D, respectively). In particular, methanol and 50\% ethanol extracts of Agrimoniae Herba displayed similar 
Plant Extracts Inhibiting Biofilm Formation by Streptococcus mutans without Antibiotic Activity

inhibitory effects, with both inhibiting biofilm formation by $55 \%$ at a concentration of $0.4 \mathrm{~g} / \mathrm{l}$. The water extract of Agrimoniae Herba suppressed biofilm formation by approximately $52 \%$ at $0.9 \mathrm{~g} / \mathrm{l}$, whereas no inhibitory activity was observed at $0.45 \mathrm{~g} / \mathrm{l}$. Concerning Polygoni Multiflori Radix, the methanol extract inhibited biofilm formation by $62 \%$ at $0.5 \mathrm{~g} / \mathrm{l}$ and $56 \%$ at $0.25 \mathrm{~g} /$. These effects were stronger than those observed for $50 \%$ ethanol and water extracts, as the latter reduced biofilm formation only at a concentration of $0.9 \mathrm{~g} / \mathrm{l}$.

Among the 140 methanol extracts of plants, nine extracts listed in Table 1 inhibited biofilm formation by S. mutans. Biofilm formation may be suppressed by inhibiting cell growth, but only Mori Cortex Radicis exerted inhibitory effects on the growth of $S$. mutans. Some plant extract also showed antibiotic activity (Koo et al., 2002; Lee et al., 2014; Park et al., 2005). These observations suggest that the methanol extracts of the remnant eight plants contain biological chemicals that selectively inhibit biofilm formation by $S$. mutans without affecting cell growth.

Mori Cortex Radicis is obtained from the root bark of Morus alba L. The methanol extract of Mori Cortex Radicis displayed excellent inhibitory activities against biofilm formation, whereas water and ethanol extracts exhibited no such activities. These results suggest that cell growth and biofilm formation by $S$. mutans are strongly inhibited by compounds selectively extracted by methanol. Previous studies observed similar strong inhibitory effects of Mori Cortex Radicis against cell growth and biofilm formation by S. mutans; researchers suggested that the compounds exhibiting the these activities were sanggenon C (Park et al., 1990) and kuwanon G (Park et al., 2003). The results consistent with previous studies showed that the method of searching for inhibitory extracts in this study is working as intended.

The inhibitory effects of Diospyros kaki leaf extract on biofilm formation by Staphylococcus aureus,
Pseudomonas aeruginosa, Escherichia coli, Salmonella typhimurium, Streptococcus mutans, and Streptococcus sanguinis have been described (Lokegaonkar and Nabar, 2010; M. Ramadan et al., 2017). It has been reported that 1-deoxynojirimycin, a compound present in Diospyros kaki leaves, possesses approximately 8-fold stronger antimicrobial and biofilm-inhibiting effects against $S$. mutans than the crude extract (Islam et al., 2008).

It has been reported that Diospyros kaki leaves inhibit the proliferation of cancer cells (Arakawa et al., 2014) and possess antiviral and antimicrobial activities (Jeong et al., 2009; Tomiyama et al., 2016). Kaempferol in Diospyros kaki leaves demonstrated antibacterial effects against S. mutans (Yamada et al., 1999). Agrimoniae Herba is the aerial part of Agrimonia pilosa Ledeb., and has been used as an anti-inflammatory (Taira et al., 2009; Jung et al., 2010), antioxidant (Zhu et al., 2009), and antibacterial agent (Yamaki et al., 1989). Polygoni Multiflori Radix is the tuberous root of Polygonum multiflorum Thunberg, a vine-like medicinal plant belonging to the Polygonaceae family. The leaves, tuberous roots, and rootstocks of this plant contain many biologically active compounds. P. multiflorum has been reported to have anticancer (Horikawa et al., 1994; Choi et al., 2007), antimicrobial (Zuo et al., 2008), antiinflammatory (Dong and Jeon, 2009), anti-oxidative (Ip et al., 1997; Chan et al., 2003; Lv et al., 2007), and liver-protective properties (Guo et al., 2001; Huang et al., 2007). Tuberous roots of $P$. multiflorum (Polygoni Multiflori Radix) have been used in Oriental medicine. Its ethanol extract is known to inhibit the enzymatic activity of $\mathrm{Ca}^{2+}$-ATPase(Grech et al., 1994).

The $50 \%$ ethanol extract of Diospyros kaki leaves and water and $50 \%$ ethanol extracts of Agrimoniae Herba and Polygoni Multiflori Radix demonstrated inhibitory activity against biofilm formation. Although antimicrobial activity has been reported for Diospyros kaki leaves, Agrimoniae Herba, and Polygoni Multiflori 
Radix, this study emphasized their inhibitory activities against biofilm formation by $S$. mutans.

In addition, the ability of water-soluble compounds to inhibit biofilm formation was examined in Fig. 3. The result suggests that compounds exhibiting antimicrobial activity may differ from those only inhibiting biofilm formation. Thus, it is necessary to optimize the extraction method in order to maximize the efficacy of the extract compound to antibiotic activity or inhibition of biofilm formation depending on purpose.

Plaque, a type of biofilm formed by S. mutans, adheres to various microorganisms causing periodontal disease and serious health problems (Peterson et al., 2013; Marsh et al., 2015). The importance of inhibiting the formation of such plaques in oral health is well known. Although several studies report agents that prevent plaque formation via their antimicrobial effects (Nakahara et al., 1993; Koo et al., 2002), there have been no reports on compounds without antimicrobial activities that selectively inhibit biofilm formation by S. mutans prior to this study. Although bactericides have the advantage of killing live bacteria, their prolonged use results in the emergence of bacterial resistance (Brauner et al., 2016; Van den Bergh et al., 2016). Therefore, naturally occurring substances that selectively inhibit biofilm formation without killing microorganisms provide a new strategy for improving oral hygiene.

\section{CONCLUSION}

Nine plant extracts inhibiting biofilm formation of S. mutans were selected from the methanol extract library of 140 plants. Among them, Diospyros kaki leaves, Agrimoniae Herba, and Polygoni Multiflori Radix retained their inhibitory effects even after extraction with water or $50 \%$ ethanol. Their water extracts did not affect cell growth but selectively inhibited biofilm formation. Selectively inhibiting biofilm formation without antibiotic activity is different from biofilm control agents in many previous studies. This study suggests the selected plants have new biofilm inhibitors that support their application for oral hygiene improvement.

\section{ACKNOWLEDGMENT}

This work was performed with support from the Cooperative Research Program for Agriculture Science and Technology Development (Project No. PJ0138960 32018), Rural Development Administration, Republic of Korea.

\section{REFERENCES}

Ahn, S.J., Ahn, S.J., Wen, Z.T., Brady, L.J., Burne, R.A. 2008. Characteristics of biofilm formation by Streptococcus mutans in the presence of saliva. Infection and Immunity 76(9): 4259-4268.

Arakawa, H., Takasaki, M., Tajima, N., Fukamachi, H., Igarashi, T. 2014. Antibacterial activities of persimmon extracts relate with their hydrogen peroxide concentration. Biological and Pharmaceutical Bulletin 37(7): 1119-1123.

Beck, J., Garcia, R., Heiss, G., Vokonas, P.S., Offenbacher, S. 1996. Periodontal disease and cardiovascular disease. Journal of Periodontology 67 Suppl 10S: 1123-1137.

Berbari, E.F., Cockerill, F.R., Steckelberg, J.M. 1997. Infective endocarditis due to unusual or fastidious microorganisms. Mayo Clinic Proceedings 72(6): 532-542.

Bowen, W.H., Koo, H. 2011. Biology of Streptococcus mutans-derived glucosyltransferases: role in extracellular matrix formation of cariogenic biofilms. Caries Research 45(1): 69-86.

Brauner, A., Fridman, O., Gefen, O., Balaban, N.Q. 
2016. Distinguishing between resistance, tolerance and persistence to antibiotic treatment. Nature Reviews Microbiology 14(5): 320-330.

Buduneli, N., Baylas, H., Buduneli, E., Turkoglu, O., Kose, T., Dahlen, G. 2005. Periodontal infections and pre-term low birth weight: a case-control study. Journal of Clinical Periodontology 32(2): 174-181.

Chan, Y.C., Wang, M.F., Chen, Y.C., Yang, D.Y., Lee, M.S., Cheng, F.C. 2003. Long-term administration of Polygonum multiflorum Thunb. reduces cerebral ischemia-induced infarct volume in gerbils. The American Journal of Chinese Medicine 31(1): 71-77.

Choi, S.G., Kim, J., Sung, N.D., Son, K.H., Cheon, H.G., Kim, K.R., Kwon, B.M. 2007. Anthraquinones, Cdc25B phosphatase inhibitors, isolated from the roots of Polygonum multiflorum Thunb. Natural Product Research 21(6): 487-493.

Dai, J., Mumper, R.J. 2010. Plant phenolics: extraction, analysis and their antioxidant and anticancer properties. Molecules 15(10): 7313-7352.

Dixon, R.A. 2001. Natural products and plant disease resistance. Nature 411(6839): 843-847.

Dong, S.C., Jeon, H. 2009 Anti-inflammatory effect of $\mathrm{MeOH}$ extracts of the stem of Polygonum multiflorum in LPS-stimulated mouse peritoneal macrophages. Natural Product Sciences 15(2): 83-89

Eley, B.M. 1999. Antibacterial agents in the control of supragingival plaque--a review. British Dental Journal 186(6): 286-296.

Glassman, P., Anderson, M., Jacobsen, P., Schonfeld, S., Weintraub, J., White, A., Gall, T., Hammersmark, S., Isman, R., Miller, C.E., Noel, D., Silverstein, S., Young, D. 2003. Practical protocols for the prevention of dental disease in community settings for people with special needs: the protocols. Special Care in Dentistry 23(5): 160-164.

Goncalves, M.O., Coutinho, W.P., Pimenta, F.P.,
Pereira, G.A., Pereira, J.A.A., Mattos-Guaraldi, A.L., Hirata, R. 2007. Periodontal disease as reservoir for multi-resistant and hydrolytic enterobacterial species. Letters in Applied Microbiology 44(5): 488-494.

Grech, J.N., Li, Q., Roufogalis, B.D., Duck, C.C. 1994. Novel $\mathrm{Ca}(2+)$-ATPase inhibitors from the dried root tubers of Polygonum multiflorum. Journal of Natural Products 57(12): 1682-1687.

Guo, X.H., Liu, Z.H., Dai, C.S., Li, H., Liu, D., Li, L.S. 2001. Rhein inhibits renal tubular epithelial cell hypertrophy and extracellular matrix accumulation induced by transforming growth factor beta1. Acta Pharmacologica Sinica 22(10): 934-938.

Ham, Y., Kim, T.J. 2016. Inhibitory activity of monoacylglycerols on biofilm formation in Aeromonas hydrophila, Streptococcus mutans, Xanthomonas oryzae, and Yersinia enterocolitica. SpringerPlus 5(1): 1526.

Harborne, J.B. 1990. Role of secondary metabolites in chemical defence mechanisms in plants. Ciba Foundation Symposium 154: 126-134.

Horikawa, K., Mohri, T., Tanaka, Y., Tokiwa, H. 1994. Moderate inhibition of mutagenicity and carcinogenicity of benzo[a]pyrene, 1,6-dinitropyrene and 3,9-dinitrofluoranthene by Chinese medicinal herbs. Mutagenesis 9(6): 523-526.

Huang, C.-H., Horng, L.-Y., Chen, C.-F., Wu, R.-T. 2007. Chinese herb Radix Polygoni Multiflori as a therapeutic drug for liver cirrhosis in mice. Journal of Ethnopharmacology 114(2): 199-206.

Islam, B., Khan, S.N., Haque, I., Alam, M., Mushfiq, M., Khan, A.U. 2008. Novel anti-adherence activity of mulberry leaves: inhibition of Streptococcus mutans biofilm by 1-deoxynojirimycin isolated from Morus alba. The Journal of Antimicrobial Chemotherapy 62(4): 751-757.

Jeon, J.G., Rosalen, P.L., Falsetta, M.L., Koo, H. 2011. 
Natural products in caries research: current (limited) knowledge, challenges and future perspective. Caries Research 45(3): 243-263.

Jeong, E.Y., Jeon, J.H., Lee, C.H., Lee, H.S. 2009. Antimicrobial activity of catechol isolated from Diospyros kaki Thunb. roots and its derivatives toward intestinal bacteria. Food Chemistry 115(3): 1006-1010.

Jeong, M.-J., Yang, J., Choi, W.-S., Kim, J.-W., Kim, S.J., Park, M.-J. 2017. Chemical compositions and antioxidant activities of essential oil extracted from Neolitsea aciculata (Blume) Koidz leaves. Journal of the Korean Wood Science and Technology 45(1): 96-106.

Jung, C.H., Kim, J.H., Park, S., Kweon, D.H., Kim, S.H., Ko, S.G. 2010. Inhibitory effect of Agrimonia pilosa Ledeb. on inflammation by suppression of iNOS and ROS production. Immunological Investigations 39(2): 159-170.

Jung, J.-Y., Yang, J.-K., Lee, W.-H. 2017. Antioxidant and safety test of natural extract of Quercus mongolica. Journal of the Korean Wood Science and Technology 45(1): 116-125.

Kim, J.-W., Um, M., Lee, J.-W. 2018. Antioxidant activities of hot water extracts from different parts of Rugosa rose (Rosa rugosa Thunb.). Journal of the Korean Wood Science and Technology 46(1): 38-47.

Kim, S.-H., Lee, S.-Y., Cho, S.-M., Hong, C.-Y., Park, S.-Y., Park, M.-J., Choi, I.-G. 2017. Antioxidant activities of Cryptomeria japonica leaves extracts by extraction methods. Journal of the Korean Wood Science and Technology 45(5): 495-510.

Koo, H., Rosalen, P.L., Cury, J.A., Park, Y.K., Bowen, W.H. 2002. Effects of compounds found in propolis on Streptococcus mutans growth and on glucosyltransferase activity. Antimicrobial Agents and Chemotherapy 46(5): 1302-1309.

Lee, S.-Y., Kim, S.-H., Park, M.-J., Lee, S.-S., Choi,
I.-G. 2014. Antibacterial activity of essential oil from Abies holophylla against respiratory tract bacteria. Journal of the Korean Wood Science and Technology 42(5): 533-542.

Li, X., Kolltveit, K.M., Tronstad, L., Olsen, I. 2000. Systemic diseases caused by oral infection. Clinical Microbiology Reviews 13(4): 547-558.

Liyana-Pathirana, C., Shahidi, F. 2005. Optimization of extraction of phenolic compounds from wheat using response surface methodology. Food Chemistry 93(1): 47-56.

Loe, H. 2000. Oral hygiene in the prevention of caries and periodontal disease. International Dental Journal 50(3): 129-139.

Loesche, W.J. 1986. Role of Streptococcus mutans in human dental decay. Microbiological Reviews 50(4): 353-380.

Lokegaonkar, S., Nabar, B. 2010. Inhibition of streptococcal biofilms using Morus alba leaf extract. Journal of Microbial World 12(2): 161-167.

Lv, L., Gu, X., Tang, J., Ho, C.-T. 2007. Antioxidant activity of stilbene glycoside from Polygonum multiflorum Thunb in vivo. Food Chemistry 104(4): 1678-1681.

M. Ramadan, E., Abou-Taleb, K., F. Galal, G., S. Abdel-Hamid, N. 2017. Antibacterial, antibiofilm and antitumor activities of grape and mulberry leaves ethanolic extracts towards bacterial clinical strains. Annals of Agricultural Sciences 62(2): 151-159.

Marsh, P.D., Head, D.A., Devine, D.A. 2015. Dental plaque as a biofilm and a microbial community-Implications for treatment. Journal of Oral Biosciences 57(4): 185-191.

Nakahara, K., Kawabata, S., Ono, H., Ogura, K., Tanaka, T., Ooshima, T., Hamada, S. 1993. Inhibitory effect of Oolong tea polyphenols on glucosyltransferases of mutans Streptococci. Applied and Environmental Microbiology 59(4): 
968-973.

Nam, J.B., Oh, G.H., Yang, S.M., Lee, S.-E., Kang, S.-G. 2018. Evaluation of antioxidant activities of water extract from microwave torrefied oak wood. Journal of the Korean Wood Science and Technology 46(2): 178-188.

Ip, S.P., Tse, S.M., Poon, M.K.T., Ko, K.-M., Ma, C.Y. 1997. Antioxidant activities of Polygonum multiflorum Thunb., in vivo and in vitro. Phytotherapy Research 11(1): 42-44.

Palombo, E.A. 2011. Traditional medicinal plant extracts and natural products with activity against oral bacteria: potential application in the prevention and treatment of oral diseases. Evidence-Based Complementary and Alternative Medicine 2011: 680354.

Park, K.M., You, J.S., Lee, H.Y., Baek, N.I., Hwang, J.K. 2003. Kuwanon G: an antibacterial agent from the root bark of Morus alba against oral pathogens. Journal of Ethnopharmacology 84(2-3): 181-185.

Park, W.J., Lee, H.J., Yang, S.G. 1990. The inhibitory effect of sanggenon $\mathrm{C}$ from the root-bark of Morus alba L. on the growth and the cellular adherence of Streptococcus mutans Yakhak Hoeji 34(6): 434-438.

Park, T., Lee, W.Y., Park, S.-Y., Ahn, J.K., Han, M.-S. 2005. Anticariogenic activity of Callistemon citrinus extract against Streptococcus mutans. Journal of the Korean Wood Science and Technology 33(2): 72-77.

Paula, V.A., Modesto, A., Santos, K.R., Gleiser, R. 2010. Antimicrobial effects of the combination of chlorhexidine and xylitol. British Dental Journal 209(12): E19.

Peterson, S.N., Snesrud, E., Liu, J., Ong, A.C., Kilian, M., Schork, N.J., Bretz, W. 2013. The dental plaque microbiome in health and disease. PLOS ONE 8(3): e58487.

Saleem, M., Nazir, M., Ali, M.S., Hussain, H., Lee,
Y.S., Riaz, N., Jabbar, A. 2010. Antimicrobial natural products: an update on future antibiotic drug candidates. Natural Product Reports 27(2): 238254.

Scannapieco, F.A. 1999. Role of oral bacteria in respiratory infection. Journal of Periodontology 70(7): 793-802.

Simoes, M., Bennett, R.N., Rosa, E.A. 2009. Understanding antimicrobial activities of phytochemicals against multidrug resistant bacteria and biofilms. Natural Product Reports 26(6): 746-757.

Song, J.H., Yang, T.C., Chang, K.W., Han, S.K., Yi, H.K., Jeon, J.G. 2007. In vitro effects of a fraction separated from Polygonum cuspidatum root on the viability, in suspension and biofilms, and biofilm formation of mutans streptococci. Journal of Ethnopharmacol 112(3): 419-425.

Taira, J., Nanbu, H., Ueda, K. 2009. Nitric oxide-scavenging compounds in Agrimonia pilosa Ledeb on LPS-induced RAW264.7 macrophages. Food Chemistry 115(4): 1221-1227.

Tomiyama, K., Mukai, Y., Saito, M., Watanabe, K., Kumada, H., Nihei, T., Hamada, N., Teranaka, T. 2016. Antibacterial action of a condensed tannin extracted from astringent persimmon as a component of food addictive pancil PS-M on oral polymicrobial biofilms. BioMed Research International 2016: 5730748.

Van den Bergh, B., Michiels, J.E., Wenseleers, T., Windels, E.M., Boer, P.V., Kestemont, D., De Meester, L., Verstrepen, K.J., Verstraeten, N., Fauvart, M., Michiels, J. 2016. Frequency of antibiotic application drives rapid evolutionary adaptation of Escherichia coli persistence. Nature Microbiology 1: 16020.

Walker, C.B. 1996. The acquisition of antibiotic resistance in the periodontal microflora. Periodontology 2000 10(1): 79-88. 
Welin-Neilands, J., Svensater, G. 2007. Acid tolerance of biofilm cells of Streptococcus mutans. Applied and Environmental Microbiology 73(17): 5633-5638.

Wolff, L.F. 1985. Chemotherapeutic agents in the prevention and treatment of periodontal disease. Northwest Dentistry 64(6): 15-24.

Yamada, Y., Yamamoto, A.Y.A., Yoneda, N., Nakatani, N. 1999. Identification of kaempferol from the leaves of Diospyros kaki and its antimicrobial activity against Streptococcus mutans. Biocontrol Science 4(2): 97-100.

Yamaki, M., Kashihara, M., Ishiguro, K., Takagi, S.
1989. Antimicrobial principles of Xian he cao (Agrimonia pilosa). Planta medica 55(2): 169-170. Zhu, L.C., Tan, J., Wang, B.C., He, R., Liu, Y.P., Zheng, C. 2009. Antioxidant activities of aqueous extract from Agrimonia pilosa LEDEB and its fractions. Chemistry \& Biodiversity 6(10): 1716-1726.

Zuo, G.Y., Wang, G.C., Zhao, Y.B., Xu, G.L., Hao, X.Y., Han, J., Zhao, Q. 2008. Screening of Chinese medicinal plants for inhibition against clinical isolates of methicillin-resistant Staphylococcus aureus (MRSA). Journal of Ethnopharmacology 120(2): 287-290. 